\title{
Senegal: Capacite a más proveedores en atención postaborto
}

Frontiers in Reproductive Health

Follow this and additional works at: https://knowledgecommons.popcouncil.org/departments_sbsr-rh

Part of the International Public Health Commons, Public Health Education and Promotion Commons, and the Women's Health Commons How does access to this work benefit you? Let us know!

\section{Recommended Citation}

"Senegal: Capacite a más proveedores en atención postaborto," FRONTERAS Resúmenes de Investigación Operativa. Ciudad de México: Population Council, 2000. 


\section{Senegal Atención postaborto}

\section{Capacite a más proveedores en atención postaborto}

\section{Antecedentes}

En Senegal, casi una de cada cinco mujeres que requiere atención obstétrica de urgencia ha tenido un aborto sin atención médica. El reconocimiento del aborto inducido inseguro como un serio problema de salud, dio como resultado que en 1997 el gobierno adoptara una estrategia nacional de salud para reducir a la mitad el número de casos de aborto inducido (aborto inseguro) para el año 2001.

Así, en 1997, el Centro de Capacitación e Investigación en Salud Reproductiva (CEFOREP) y la Clínica de Ginecología y Obstetricia (CGO) del Hospital Universitario Le Dantec, en Dakar, introdujo nuevas técnicas clínicas para mejorar la atención de urgencia que se ofrece a las mujeres con complicaciones ocasionadas por un aborto inducido o espontáneo. La CGO y otros dos hospitales universitarios participaron como centros piloto. Los médicos, enfermeras y parteras de estos tres centros de salud, recibieron capacitación en aspiración manual endouterina (AMEU), planificación familiar y consejería. El Fondo de Población de las Naciones Unidas y la corporación JHPIEGO contribuyeron con equipo, apoyo logístico y capacitación.
Para medir el impacto de la capacitación, CEFOREP entrevistó a 320 mujeres que recibieron tratamiento de urgencia y a 204 proveedores, antes de la intervención, y a 543 pacientes y a 175 proveedores, después de la intervención. Se obtuvo también información sobre los costos de prestación del servicio.

\section{Resultados}

Después de la capacitación, los proveedores rápidamente decidieron adoptar la AMEU como el procedimiento preferido entre otras técnicas clínicas.

Aumentar el acceso a servicios de APA y mejorar los procedimientos de referencia podría salvar a más mujeres

Los cambios en el manejo del servicio redujeron la estancia hospitalaria a casi la mitad, es decir, a 1.2 días en promedio. Aunque los costos para las pacientes se redujeron en un 25 por ciento (26,700 Francos CFA ó US \$46), dichos costos siguen siendo elevados para ellas (véase Tabla 1). 
La comunicación entre prestadores y pacientes mejoró. Las pacientes recibieron más información sobre el tratamiento y más apoyo psicológico. Sin embargo, el apoyo verbal no redujo la necesidad de recurrir a la anestesia local para controlar el dolor.

Después de la intervención, la proporción de pacientes que recibió consejería sobre planificación familiar se duplicó. De las que recibieron este servicio, la proporción de mujeres que decidió utilizar un método anticonceptivo aumentó de un 56 a un 76 por ciento.

\section{Implicaciones normativas}

Aumentar el acceso a los servicios de APA y mejorar los procedimientos de referencia podría salvar la vida de más mujeres. Más de dos de cada tres pacientes entrevistadas había acudido a dos o más hospitales antes de recibir tratamiento, lo que retrasó su atención hasta 4.7 días desde el comienzo de los síntomas.

Los servicios de consejería en PF se deben proporcionar sistemáticamente a todas las pacientes postaborto.

La capacitación en APA se debe ampliar para incluir a más médicos, parteras y enfermeras. Los medicamentos para controlar el dolor son esenciales. Los consumibles y el equipo para la APA deben incluirse en los presupuestos de hospitales y clínicas.

Tabla 1. Beneficios de la atención postaborto mejorada

\begin{tabular}{lcc}
\hline & $\begin{array}{c}\text { Antes de la } \\
\text { capacitación }\end{array}$ & $\begin{array}{c}\text { Después de la } \\
\text { capacitación }\end{array}$ \\
\hline Pacientes admitidas inmediatamente para tratamiento & $55 \%$ & $69 \%$ \\
\hline Duración de la estancia hospitalaria - dos hospitales & 2.3 días & 1.2 días \\
\hline Costo para la paciente & $\begin{array}{c}35,800 \text { CFA* } \\
\text { (US\$61) }\end{array}$ & $\begin{array}{c}27,700 \text { CFA* } \\
\text { (US\$46) }\end{array}$ \\
\hline Pacientes que recibieron consejería en PF & $18 \%$ & $34 \%$ \\
\hline $\begin{array}{l}\text { De las pacientes que recibieron consejería, } \\
\text { porcentaje que recibió un anticonceptivo }\end{array}$ & $56 \%$ & $76 \%$ \\
\hline * Francos Centro Africanos & & Febrero 2000 \\
\hline
\end{tabular}

Este proyecto fue posible gracias al apoyo de la Agencia de los Estados Unidos para el Desarrollo Internacional (USAID) bajo el contrato número CCP-3030-C-00-3008-00 y el Acuerdo de Cooperación número HRN-A-00-98-00012-00 